\title{
Predicting, treating and preventing postoperative recurrence of Crohn's disease: The state of the field
}

\author{
Anna M Borowiec MD ${ }^{1}$, Richard N Fedorak MD FRCPSC ${ }^{2}$
}

\begin{abstract}
AM Borowiec, RN Fedorak. Predicting, treating and preventing postoperative recurrence of Crohn's disease: The state of the field. Can J Gastroenterol 2011;25(3):140-146.
\end{abstract}

The majority of patients diagnosed with Crohn's disease eventually require surgical intervention. Unfortunately, postsurgical remission tends to be short lived; a significant number of patients experience clinical relapse and many require additional operations. The pathogenesis of this postoperative recurrence is poorly understood and, currently, there are no reliable tools to predict when and in whom the disease will recur. Furthermore, the postoperative prophylaxis profiles of available Crohn's disease therapeutic agents such as 5-aminosalicylates, immunomodulators, steroids and probiotics have been disappointing. Recently, the combination of antibiotics and azathioprine in selected high-risk patients has demonstrated some potential for benefit. The goal of the present article is to provide a coherent summary of previous and new research to guide clinicians in managing the challenging and complex problem of postoperative Crohn's disease recurrence.

Key Words: Azathioprine; Corticosteroids; Crohn's disease; Ileocolonic resection; Infliximab; Mesalamine; Postoperative recurrence; Probiotics

rohn's disease (CD) is a chronic inflammatory gastrointestinal (GI) disorder that can affect any portion of the GI tract. At diagnosis, $47 \%$ of patients have localized disease in the terminal ileum, and $21 \%$ experience involvement of the ileocolon (1). CD is most prevalent in North America and Europe, with an estimated occurrence of $0.2 \%$ in the United States and central Canada; peak incidence occurs in the second decade of life $(2,3)$. The etiology of CD remains unclear; however, a combination of genetic predisposition, several bacterial agents and environmental factors are most likely responsible for disease onset and progression.

There is no cure for CD - the goal of medical and surgical therapies is symptom relief. Medical management is the first line of therapy, while surgery is reserved for patients who experience refractory symptoms despite optimized medical management, and for the treatment of complications. The most common indications for surgery are failure of medical management and obstruction (4). It has been estimated that $75 \%$ of $\mathrm{CD}$ patients eventually require surgery within 20 years of symptom onset (5). The goal of the present review is to discuss the available surgical management options, postoperative recurrence rates and patterns, tools for predicting recurrence and, finally, postoperative preventive and therapeutic choices.

\section{SURGICAL MANAGEMENT OF CD}

The goals of surgical therapy for $\mathrm{CD}$ are to alleviate symptoms while limiting or preventing bowel resection, and to minimize the risk of complications such as short bowel syndrome.

The most commonly performed operations are stricturoplasties and bowel resections. A stricturoplasty conserves bowel length by widening a narrowed lumen without bowel resection. A common indication for stricturoplasty is a short segment stricture within the jejunum and ileum (6).

\author{
Prédire, traiter et prévenir la récurrence \\ postopératoire de maladie de Crohn : l'état de la \\ situation
}

La majorité des patients ayant un diagnostic de maladie de Crohn finissent par devoir se faire opérer. Malheureusement, la rémission postchirurgicale tend à être de courte durée. En effet, de nombreux patients font une rechute clinique et bon nombre doivent subir de nouvelles opérations. La pathogenèse de cette récurrence postopératoire est mal comprise et, à l'heure actuelle, il n'existe aucun outil fiable pour prédire quand la maladie récidivera et qui cette récidive touchera. De plus, les profils prophylactiques postopératoires des agents thérapeutiques offerts contre la maladie de Crohn, tels que les 5-aminosalicylates, les immunomodulateurs, les stéroïdes et les probiotiques, sont décevants. Récemment, l'association d'antibiotiques et d'azathioprine chez des patients à haut risque sélectionnés a démontré un certain potentiel de bienfaits. Le présent article vise à fournir un sommaire cohérent des recherches passées et nouvelles, afin d'orienter les cliniciens dans la prise en charge du problème difficile et complexe de la récurrence de maladie de Crohn.

Of patients referred for surgery, $40 \%$ to $50 \%$ have disease of the terminal ileum, which requires resection due to perforation, fistulas or a long strictured segment (4). The estimated probability of ileocolonic resection after an average of 13 years of disease activity in the terminal ileum is $91.5 \%(7)$.

\section{Postoperative recurrence of CD}

Surgical management of CD offers immediate resolution of acute symptoms; however, surgical success tends to be short lived. Despite advances in the medical treatment of $\mathrm{CD}$, the overall reported postoperative recurrence rates remain high, with clinical relapses of $17 \%$ to $55 \%$ at five years, $32 \%$ to $76 \%$ at 10 years, and $70 \%$ at 20 years (8). Furthermore, a considerable number of patients with recurrent $\mathrm{CD}$ will require subsequent operations, which are more complex procedures and are associated with an increased risk of morbidity (9). The estimated overall incidence of reoperation is $11 \%$ to $32 \%$ at five years, $20 \%$ to $44 \%$ at 10 years, and $46 \%$ to $55 \%$ at 20 years (8).

Both the site of the initial operation and the surgical procedure performed influence the pattern and rate of recurrence. A large meta-analysis of 1112 patients who underwent 3259 stricturoplasties (94\% of cases) involving the jejunum and/or ileum (6) revealed recurrence rates requiring reoperation in $14 \%$ of patients at five years. By comparison, patients with surgically treated ileocolonic disease tended to experience a higher frequency of reoperation at the same time interval (53\%) (10). Interestingly, the site of recurrence among $90 \%$ of these stricturoplasty patients was remote from the original site of operation (6). In contrast, a retrospective study of $78 \mathrm{CD}$ patients who underwent reoperation (11) found recurrence at the previous anastomosis in $70 \%$ of bowel resection cases. In addition, the disease recurred at the anastomosis site for $83 \%$ of patients who had previously undergone ileocecal resection, and the inflammation extended into the proximal limb of the neoterminal ileum.

Department of Surgery, Division of General Surgery; ${ }^{2}$ Department of Medicine, Division of Gastroenterology, University of Alberta, Edmonton, Alberta

Correspondence: Dr Anna M Borowiec, Department of Surgery, Division of General Surgery, University of Alberta, Ziedler Ledcor Building, Edmonton,

Alberta T6G 2X8. Telephone 780-492-6941, fax 780-492-8121, e-mail amb1@ualberta.ca

Received for publication May 5, 2010. Accepted September 30, 2010 
For ileocecal resection, the pathogenesis leading to clinical symptoms appears to occur in the immediate postoperative period. Up to $72 \%$ of patients show endoscopic evidence of disease such as aphthous ulcers in the neoterminal ileum in the first postoperative year; however, only 20\% experience symptoms (12). Clinical follow-up and endoscopy at three and 10 years show progressively more severe bowel wall disease activity, and a progressive increase in CD symptoms (12). These early postoperative changes present an opportunity for early intervention.

\section{Risk factors for postoperative recurrence of CD}

Patient factors: Patient factors such as age at disease onset, sex and use of oral contraceptives have been investigated; however, none of these factors are currently considered to be predictors of disease recurrence (13-16). Strikingly, a large volume of evidence indicates that tobacco smoking is an independent risk factor for endoscopic, clinical and surgical recurrence $(14,16-21)$. The data on smoking were summarized in a recent, large meta-analysis of 2962 patients (22) in which CD patients who were smokers were shown to have 2.5-fold increased risk of surgical recurrence and a twofold increased risk of clinical recurrence compared with nonsmokers. This high risk of postoperative relapse and reoperation is significantly reduced if a patient quits smoking (22).

Disease factors: Disease-associated factors that have been implicated in early postoperative recurrence include the duration of disease before initial surgical therapy and the presence of perforating disease activity. Based on mixed results from studies conducted both in adults and children (13,23-27), the relationship between the duration of disease and its recurrence remains inconclusive.

$\mathrm{CD}$ follows one of the three following behaviour patterns: nonstricturing and nonperforating; stricturing; or perforating (least common) (1). Perforating CD is characterized by the development of acute-free perforations, abscesses or fistulas, and appears to represent a more complex and aggressive form of the disease that results in earlier postoperative recurrence. This is supported by a review of 770 patients (28) showing that individuals with perforating disease were more likely to require reoperation for recurrent perforation, and required reoperation two times earlier than did patients with nonperforating disease. However, the early recurrence of perforating disease has not been supported by several studies $(23,29,30)$ including a meta-analysis of 3044 patients (31). Although the results of the meta-analysis showed significantly increased risk of reoperation for patients with perforating disease, these results must be interpreted with caution due to the significant differences in these studies' designs. However, one thing is certain: the type of disease requiring surgical intervention predicts the type of recurrent disease - perforating disease leads to perforating recurrence, while nonperforating disease recurs as a nonperforating disease (31).

Surgical factors: The risk factors associated with surgical technique have been explored in depth, thereby enabling advances in surgical procedures and techniques that optimize postoperative outcomes. Factors such as the length of bowel resected, resection of microscopically positive margins, number of resections, presence of granulomas in the resected specimen and postoperative complications have not been consistently shown to be predictive of disease recurrence (15,23,32-36).

Most surgeons use a minimalist philosophy in the surgical treatment of CD by removing grossly diseased bowel and leaving behind margins that may harbour microscopic disease. The adequacy of this approach was confirmed in a prospective trial (37) in which no difference in recurrence was noted between patients randomly assigned to undergo $2 \mathrm{~cm}$ versus $12 \mathrm{~cm}$ resection margins. This approach minimizes bowel loss to prevent short gut syndrome.

Disease recurrence at the anastomosis is a well-recognized fact, which has prompted close examination of surgical anastomosis techniques (11). Retrospective studies $(14,38-41)$ have provided conflicting evidence on the best anastomotic technique (staples versus hand sewn) and configuration (end-to-end versus side-to-side). However, a recent prospective trial (42) comparing stapled side-to-side anastomosis with hand-sewn end-to-end anastomosis showed no difference between the two groups with respect to endoscopic and clinical recurrence at 12 months, thus making either choice appropriate.

An advance in the surgical management of $C D$ in the past couple of decades has been the introduction and widespread use of laparoscopic bowel resections. This approach is best suited to patients undergoing elective operations, and should be used with caution or avoided completely in the setting of diffuse peritonitis, complex fistulae, dense adhesions or emergency. Laparoscopy offers multiple benefits including lower postoperative morbidity, faster GI functional recovery, reduction in blood transfusions, reduction in postoperative narcotic use, and shorter length of hospital stay, in addition to a more desirable cosmesis without increase in recurrence rates as demonstrated in shortterm and long-term follow-up studies (43-47).

\section{Predicting postoperative recurrence of CD}

Currently, there are no clear guidelines for postoperative prophylaxis or follow-up. The lack of standard postoperative care guidelines stems from an incomplete understanding of the pathogenesis of postoperative $\mathrm{CD}$ recurrence, the limited number of efficacious prophylactic interventions available and an inability to reliably risk-stratify patients. Identification and risk stratification of patients are key steps in postoperative care for individuals who need treatment, and to avoid lifelong treatment and its potential adverse events in those who do not. A countless number of attempts at solving this dilemma were and continue to be - made in the areas of radiology, genetics and immunology. Examples include imaging modalities such as ultrasound, virtual colonoscopy, capsule endoscopy and magnetic resonance, as well as the testing of fecal contents for alpha 1-antitrypsin and calprotectin, local and systemic production of proinflammatory cytokines such as tumour necrosis factor, interleukin- 6 and interleukin- 1 beta, the production of specific antimicrobial antibodies and genetic variability in the NOD2/CARD15 gene (48-63). Although these studies contributed invaluable knowledge to the understanding of $\mathrm{CD}$, their clinical applicability is presently limited.

\section{MANAGEMENT OF POSTOPERATIVE CD}

\section{5-aminosalicylates (Table 1)}

5-aminosalicylate (ASA) and its derivatives, mesalamine and sulfasalazine, are anti-inflammatory agents that decrease local bowel inflammation and can be formulated to target specific GI sites. The available evidence suggests that sulfasalazine has limited effectiveness in preventing postoperative recurrence. Two small randomized controlled trials using sulfasalazine at $5 \mathrm{~g} /$ day and $3 \mathrm{~g} /$ day versus placebo $(64,65)$ showed no difference in terms of clinical recurrence at one year. A multicentre trial of 232 patients receiving daily sulfasalazine ( $3 \mathrm{~g} /$ day) or placebo (66) showed a reduction in the endoscopic, clinical and radiological recurrence rates in the treatment group at one year; however, no difference was observed at the three-year follow-up.

Eight randomized controlled trials using mesalamine (67-74) have been conducted, seven of which compared mesalamine with placebo and one that compared it with 6-mercaptopurine (6-MP). The first two moderately sized, controlled studies of 110 and 163 patients, using $2.4 \mathrm{~g} /$ day and $3 \mathrm{~g} /$ day of mesalamine, respectively $(67,68)$, reported positive effects. The patients using $2.4 \mathrm{~g} /$ day had lower rates of endoscopic and symptomatic recurrence at two years, while patients taking $3 \mathrm{~g} /$ day had lower symptomatic recurrence rates over the course of the six-year follow-up period. Two subsequent studies $(69,70)$, however, did not show any statistical significance in favour of mesalamine, and a third study of 87 patients on $3 \mathrm{~g} /$ day of mesalamine (71) reported less severe lesions on endoscopy at 12 months. Three randomized, controlled trials that followed also failed to demonstrate strong benefits for mesalamine. One of these trials (72), the largest multicentre controlled trial to date, enrolled 318 patients who received $4 \mathrm{~g} /$ day of mesalamine, did not demonstrate a difference in the recurrence rates between the treatment and the placebo groups at 18 months. However, subgroup analysis showed lower relapse rates among the mesalamine 
TABLE 1

Summary of evidence supporting the use of 5-aminosalicylates for the prevention of postoperative recurrence of Crohn's disease

\begin{tabular}{|c|c|c|c|c|c|}
\hline Author (reference), year & Study type & $\mathbf{n}$ & Treatment & Primary outcome* & $\mathbf{P}$ \\
\hline Wenckert et al (65), 1978 & $\mathrm{RCT}$ & 66 & Sulfasalazine $3 \mathrm{~g} /$ day versus placebo & Clinical at 1 year & NS \\
\hline Summers et al (64), 1979 & $\mathrm{RCT}$ & 28 & Sulfasalazine $5 \mathrm{~g} /$ day versus placebo & Clinical at 1 year & NS \\
\hline Ewe et al (66), 1989 & $\mathrm{RCT}$ & 232 & Sulfasalazine $3 \mathrm{~g} /$ day versus placebo & $\begin{array}{l}\text { Endoscopic at } 1 \text { year; } \\
\text { radiological at } 1 \text { year; } \\
\text { clinical at } 1 \text { year }\end{array}$ & $<0.01$ \\
\hline Caprilli et al (67), 1994 & $\mathrm{RCT}$ & 110 & Mesalamine $2.4 \mathrm{~g} /$ day versus placebo & $\begin{array}{l}\text { Endoscopic at } 2 \text { years; } \\
\text { clinical at } 2 \text { years }\end{array}$ & $<0.05$ \\
\hline McLeod et al (68), 1995 & $\mathrm{RCT}$ & 163 & Mesalamine $3 \mathrm{~g} /$ day versus placebo & Clinical at 6 years & 0.03 \\
\hline Brignola et al (69), 1995 & $\mathrm{RCT}$ & 87 & Mesalamine $3 \mathrm{~g} /$ day versus placebo & $\begin{array}{l}\text { Endoscopic at } 1 \text { year; } \\
\text { clinical at } 1 \text { year }\end{array}$ & NS \\
\hline Florent et al (70), 1996 & $\mathrm{RCT}$ & 126 & Mesalamine $3 \mathrm{~g} /$ day versus placebo & Endoscopic at 3 months & NS \\
\hline Sutherland et al (71), 1997 & $\mathrm{RCT}$ & 66 & Mesalamine $3 \mathrm{~g} /$ day versus placebo & Clinical at 1 year & NS \\
\hline Lochs et al (72), 2000 & $\mathrm{RCT}$ & 318 & Mesalamine $4 \mathrm{~g} /$ day versus placebo & Clinical at 18 months & NS \\
\hline Caprilli et al (73), 2003 & $\mathrm{RCT}$ & 165 & Mesalazine $4 \mathrm{~g} /$ day versus $2.4 \mathrm{~g} /$ day & Endoscopic at 1 year & NS \\
\hline Hanauer et al (74), 2004 & $\mathrm{RCT}$ & 131 & Mesalamine $3 \mathrm{~g} /$ day versus 6-MP 50 mg/day & $\begin{array}{l}\text { Endoscopic at } 2 \text { years; } \\
\text { radiological at } 2 \text { years; } \\
\text { clinical at } 2 \text { years }\end{array}$ & NS \\
\hline
\end{tabular}

${ }^{\star}$ Primary outcome = recurrence rates (endoscopic, radiological, clinical or surgical). 6-MP 6-mercaptopurine; AZA Azathioprine; NS Not statistically significant (P>0.05); RCT Randomized controlled trial

TABLE 2

Summary of evidence supporting the use of immunomodulators in the prevention of postoperative recurrence of Crohn's disease

\begin{tabular}{|c|c|c|c|c|c|}
\hline Author (reference), year & Study type & $\mathbf{n}$ & Treatment & Primary outcome* & $\mathbf{P}$ \\
\hline \multirow[t]{2}{*}{ Cuillerier et al (76), 2001} & Retrospective case series & 38 & AZA mean dose 2 mg/kg/day & Clinical at 1, 2 and 3 years & NA \\
\hline & & & & Endoscopic at 1, 2 and 3 years & \\
\hline Domenech et al (77), 2004 & Retrospective case series & 33 & AZA vs mesalazine(variable doses) & $\begin{array}{l}\text { Clinical and endoscopic during } \\
4 \text { years }\end{array}$ & $<0.05$ \\
\hline Hanauer et al (74), 2004 & $\mathrm{RCT}$ & 131 & 6-MP 50 mg/day vs mesalamine 3 g/day & Endoscopic at 2 years & $<0.05$ \\
\hline Ardizzone et al (81), 2004 & Open-label prospective & 142 & AZA 2 mg/kg/day vs mesalamine 3 g/day & Clinical at 2 years & NS \\
\hline D'Haens et al (79), 2008 & RCT & 81 & Abx with AZA $100-150$ mg/day vs Abx with placebo & Endoscopic at 1 year & $<0.05$ \\
\hline
\end{tabular}

*Primary outcome = recurrence rates (endoscopic, radiological, clinical or surgical). 6-MP 6-mercaptopurine; Abx Antibiotic (metronidazole 250 mg three times daily or ornidazole 500 mg twice daily); AZA Azathioprine; NA Not applicable because recurrence rate was reported, but no P value was calculated; NS Not statistically significant ( $P>0.05)$; RCT Randomized controlled trial; vs Versus

patients whose disease was isolated to the small bowel. A more recent meta-analysis from the Cochrane Collaboration examining mesalamine versus placebo (75) reported a reduction in the RR of clinical recurrence, but no effect on overall endoscopic recurrence. This particular meta-analysis confirmed good compliance with mesalamine and a low risk of adverse events.

Immunosuppressants (Table 2)

The immunosuppressors 6-MP and azathioprine (AZA) are purine analogues that interfere with DNA, RNA and protein synthesis, causing global downregulation of the immune system. In combination with an antibiotic, the use of these agents currently comprise the best evidence supporting their prophylactic use in the prevention of $\mathrm{CD}$ relapse following surgery.

A few small retrospective studies (76-78) reported that immunosuppressors may be of benefit in lowering postoperative clinical and endoscopic recurrence rates. However, only two randomized controlled trials have been conducted to date $(74,79)$, one comparing 6-MP (50 mg/day) with mesalamine ( $3 \mathrm{~g} /$ day $)$ and placebo, and the second examining a combination of antibiotic (metronidazole $250 \mathrm{mg}$ three times daily or ornidazole $500 \mathrm{mg}$ twice daily) for the first 12 weeks along with AZA (100 mg/day to $150 \mathrm{mg} /$ day) or placebo for one year. The first study (74) found 6-MP to be more effective in reducing postoperative endoscopic and clinical recurrence than were mesalamine or placebo at two years; however, these results must be interpreted with caution. The study was criticized for overestimating clinical relapse in the placebo group, having a high dropout rate, a lack of primary outcome measure definition, a flawed statistical analysis and a dose of 6-MP that was possibly too low (80).

In the second study examining the combination of an antibiotic and AZA (79), 81 high-risk patients (with more than one of the following risk factors: younger than 30 years of age; active smoker; corticosteroid used in the three-month preoperative period; second, third or fourth resection; and perforating disease) who had undergone ileal or ileocolonic resection were treated with daily metronidazole or ornidazole for three months plus AZA or placebo then, after three months, continued on AZA or placebo for 40 weeks. The primary outcomes were defined as endoscopic recurrence with a Rutgeerts' score of greater than 2 at three and 12 months (79). There was no difference in endoscopic recurrence between the two groups at three months; however, patients treated with AZA experienced a significantly lower rate of endoscopic recurrence at 12 months (55\%) than did the patients who received placebo (78\%).

An open-label prospective trial comparing AZA ( $2 \mathrm{mg} / \mathrm{kg} / \mathrm{day})$ with mesalamine ( $3 \mathrm{~g} /$ day) (81) did not reveal a difference with respect to clinical and surgical recurrence rates at two years following conservative surgery for CD. However, subgroup analysis did show that, among the patients who underwent a previous bowel resection, those treated with AZA had lower relapse rates. Similarly, the potential benefit 
TABLE 3

Summary of evidence for the use of steroids for the prevention of postoperative recurrence of Crohn's disease

\begin{tabular}{|c|c|c|c|c|c|}
\hline Author (reference), year & Study type & $\mathbf{n}$ & Treatment & Primary outcome* & $\mathbf{P}$ \\
\hline Bergman et al (85), 1976 & RCT & 97 & Sulfasalazine with prednisolone versus placebo & Clinical at 1,2 and 3 years & NS \\
\hline Ewe et al (87), 1999 & RCT & 83 & Budesonide $3 \mathrm{mg} /$ day versus placebo & Endoscopic at 3 months, 1 year & NS \\
\hline
\end{tabular}

*Primary outcome = recurrence rates (endoscopic, radiological, clinical or surgical). NS Not statistically significant (P>0.05); RCT Randomized controlled trial

\section{TABLE 4}

Summary of evidence for the use of antibiotics and probiotics for prevention of postoperative recurrence of Crohn's disease

\begin{tabular}{|c|c|c|c|c|c|}
\hline Author (reference), year & Study type & $\mathbf{n}$ & Treatment & Primary outcome* & $\mathbf{P}$ \\
\hline Rutgeerts et al (89), 1995 & $\mathrm{RCT}$ & 60 & Metronidazole 20 mg/kg versus placebo & Endoscopic at 3 months & NS \\
\hline Rutgeerts et al (90), 2005 & $\mathrm{RCT}$ & 80 & Ornidazole $1 \mathrm{~g} /$ day versus placebo & $\begin{array}{l}\text { Endoscopic at } 1 \text { year, } \\
\text { clinical at } 1 \text { year }\end{array}$ & $<0.05$ \\
\hline Prantera et al (92), 2002 & $\mathrm{RCT}$ & 45 & Lactobacillus GG & Endoscopic at 1 year & NS \\
\hline Marteau et al (93), 2006 & $\mathrm{RCT}$ & 98 & Lactobacillus johnsonii LA1 & Endoscopic at 6 months & NS \\
\hline Van Gossum et al (94), 2007 & $\mathrm{RCT}$ & 70 & Lactobacillus johnsonii LA1 & Endoscopic at 3 months & NS \\
\hline Chermesh et al (95), 2007 & $\mathrm{RCT}$ & 30 & Synbiotic 2000 versus placebo & Endoscopic at 3 months & NS \\
\hline Madsen et al (96), 2008 & $\mathrm{RCT}$ & 120 & VSL\#3 ${ }^{\dagger}$ vs placebo & $\begin{array}{c}\text { Endoscopic at } 3 \text { months, } \\
\text { endoscopic at } 1 \text { year }\end{array}$ & $\begin{array}{l}\text { NS } \\
<0.05\end{array}$ \\
\hline
\end{tabular}

${ }^{*}$ Primary outcome = recurrence rates (endoscopic, radiological, clinical or surgical); ${ }^{\dagger}$ VSL Pharmaceuticals Inc, USA. NS Not statistically significant (P>0.05); RCT Randomized controlled trial

of AZA and 6-MP in patients who had undergone multiple bowel surgeries was shown in a small retrospective study in which patients treated with these immunosuppressants were found to be less likely to undergo a third intestinal resection (82). In a more recent open-label prospective study (83), 56 patients who underwent curative intestinal resection were treated with daily AZA ( $2 \mathrm{mg} / \mathrm{kg} /$ day to $2.5 \mathrm{mg} / \mathrm{kg} / \mathrm{day})$ starting immediately after surgery. The cumulative probabilities of endoscopic postoperative relapse based on this study were $44 \%, 53 \%$, $69 \%$ and $82 \%$ at one, two, three and five years, respectively. The authors interpreted these results to indicate that early initiation of postoperative AZA treatment delayed endoscopic recurrence. The importance of this 'delay' depends on what one considers to be the natural postoperative recurrence rate. For example, the classical study conducted by Renna et al (84) in 1984 showed evidence of endoscopic recurrence in 70\% of patients at one year; however, a recent meta-analysis of postoperative placebo treatment reported a pooled estimate of $50.2 \%$ for the one-year severe endoscopic recurrence rate, with significant heterogeneity being exhibited among the studies used $(12,83)$. In addition, $36 \%$ of patients in this 56-patient study experienced adverse effects from the AZA - the most common being lymphopenia (84).

The evidence supporting the use of immunosuppressants in the postoperative setting is summarized in a recent Cochrane Collaboration meta-analysis by Doherty et al (75). The authors concluded that AZA/6-MP therapy was associated with a significantly reduced risk of clinical and severe endoscopic recurrence compared with placebo. However, one must be reminded of the potential adverse effects associated with the use of these agents.

Steroids (Table 3)

Steroids play a very limited role in the maintenance of medically induced CD remission, and have no documented role in preventing the postoperative recurrence of $\mathrm{CD}(85-88)$.

\section{Antibiotics and probiotics (Table 4)}

The commensal GI bacteria have been implicated in the pathogenesis of $\mathrm{CD}$, and agents targeting bacterial flora, in theory, should have an effect on the disease itself. Two randomized controlled trials examining antibiotic treatment in the postoperative context have been conducted $(89,90)$. In the first study (89), 60 patients were randomly assigned to metronidazole $(20 \mathrm{mg} / \mathrm{kg})$ or placebo for three months immediately after ileocolonic resection surgery. Patients receiving the antibiotic were found to have significantly less severe endoscopic disease at 12 weeks postoperatively and lower recurrence rates at one year, but no improvement in relapse rates at two and three years - findings suggesting that antibiotics delay postoperative recurrence.

Ornidazole $(1 \mathrm{~g} /$ day $)$ was also shown to be more effective than placebo in a randomized controlled trial of 80 patients (90) in which the treatment group experienced significantly lower postoperative endoscopic and clinical recurrences at 12 months after ileocolonic resection. Despite these positive findings, there was a high dropout rate for both studies due to adverse treatment side effects including metallic taste and GI upset. The recent study (79) that combined three months of lower dose metronidazole ( $250 \mathrm{mg}$ three times daily) with continuous AZA demonstrated a reduction in endoscopic recurrence, and may have solved the issue of high-dose antibiotic use.

Probiotics are nonpathogenic gut bacteria that can improve intestinal microbial balance. Studies of probiotics in recent years have revealed a variety of mechanisms through which these microbes benefit the host including modulation of epithelial cell-barrier function and epithelial cytokine secretion, as well as exertion of antibacterial effects through the secretion of antimicrobial peptides and competition with other microbes for colonization (91). To date, however, four of five randomized controlled trials (92-96) have not provided supporting evidence encouraging the use of probiotics in the prevention of postoperative recurrence. For example, endoscopic recurrence was not prevented at one year after bowel resection using a 12-month administration of Lactobacillus GG, or at three and six months in patients receiving Lactobacillus johnsonii LA1 (92-94). Similarly, treatment with a combination of prebiotics and probiotics (Synbiotic 2000 [a mixture of prebiotics and probiotics, including four lactic acid bacteria and four fermentable fibres. The four lactic acid bacteria are as follows: 1010 Pediococcus pentosaceus, 1010 Lactococcus raffinolactis, 1010 Lactococcus paracasei subsp paracasei 19 and 1010 Lactococcus plantarum 2362. The four fermentable fibres are $2.5 \mathrm{~g}$ beta-glucans, $2.5 \mathrm{~g}$ inulin, $2.5 \mathrm{~g}$ pectin and $2.5 \mathrm{~g}$ resistant starch]) did not result in improved endoscopic injury scores at three and 24 months after surgery (95). In contrast, one study that used a combination of probiotics (VSL\#3, VSL Pharmaceuticals Inc, USA) (96) showed a trend toward decreased severity of endoscopic CD recurrence at one year among patients receiving the probiotic, which was not statistically significant. Furthermore, in the same study, VSL $\# 3$ had a marked downregulating effect on mucosal proinflammatory cytokine expression. Presently, there is no evidence to support the routine use of probiotics in the postoperative setting. 


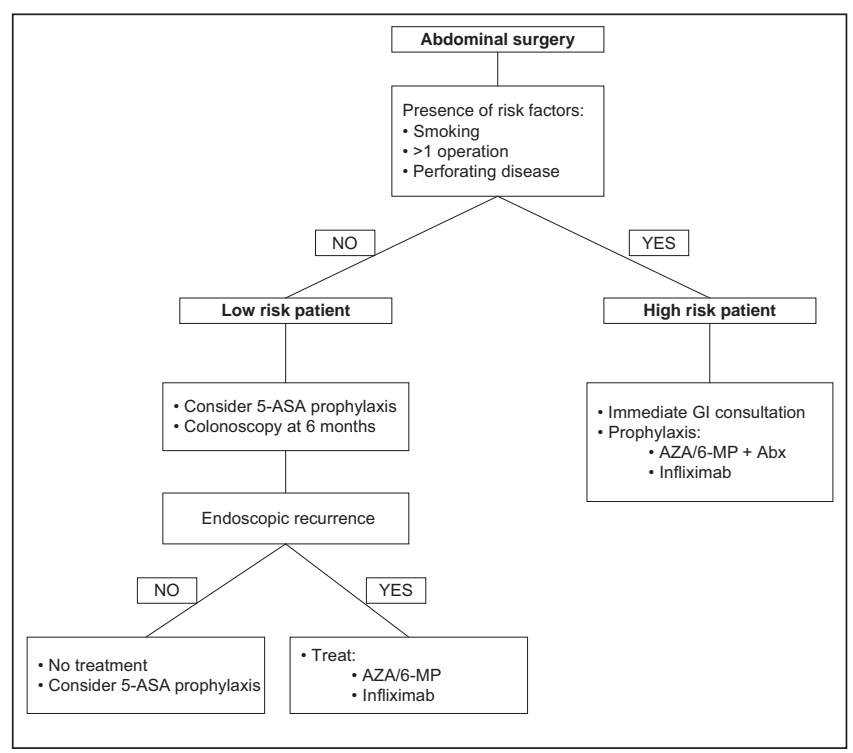

Figure 1) Recommended approach to patients undergoing surgery for Crohn's disease. 6-MP 6-Mercaptopurine; Abx Antibiotic; 5-ASA 5-Aminosalicylate; AZA Azathioprine; GI Gastroenterological

\section{Biologicals}

Although promising, the evidence supporting the use of infliximab in the postoperative setting is still based on limited experience consisting of one case report, a small nonrandomized prospective study and two small randomized controlled trials (97-100). In the case report (97), a 23-year-old woman remained free of endoscopic and clinical recurrence at four years postsigmoid resection while on a combination treatment of intravenous infliximab $(5 \mathrm{mg} / \mathrm{kg})$ every eight weeks and a low weekly dose of oral methotrexate $(10 \mathrm{mg} /$ week). Following the same regimen after various surgical interventions (ileal, ileocolonic and sigmoid resections), seven patients experienced no endoscopic or clinical recurrence at two years after surgery compared with a control group of 16 patients receiving daily mesalamine $(2.4 \mathrm{~g} / \mathrm{day})$ that experienced a $75 \%$ recurrence rate at the time of follow-up (98). To date, the best evidence supporting the postoperative use of infliximab comes from a study of 24 patients randomly assigned to $5 \mathrm{mg} / \mathrm{kg}$ intravenous injections of infliximab or placebo for one year (99). The patients receiving infliximab had significantly lower endoscopic and histological recurrence rates at one year postileocolonic resection; however, clinical recurrence, although lower in the treatment group, did not reach statistical significance. Infliximab was also proven to be more effective than mesalamine and AZA in salvage therapy once endoscopic recurrence was confirmed at six months after surgery (100). In a small study of 26 patients (100), eight patients with endoscopic recurrence randomly assigned to infliximab did not progress to clinical recurrence over the next six months, and showed improvement in mucosal inflammation over the same period. By comparison, 38\% and $70 \%$ of patients developed clinical recurrence when treated with AZA and mesalamine, respectively.

\section{Other strategies}

Interleukin-10 (IL-10) is an anti-inflammatory cytokine that ameliorates inflammation in an IL-10-deficient murine model of CD. In addition, low levels of ileal IL-10 messenger RNA in humans at the time of surgery has been shown to predict early recurrence (101). The subcutaneous administration of recombinant human IL-10 (Tenovil, Schering-Plough, USA) in a randomized controlled trial of 58 patients after ileocolonic resection (102) did not prevent endoscopic recurrence at 12 weeks.

\section{SUMMARY AND CLINICAL APPLICATION}

Despite ongoing efforts, there remains a lack of firm, evidence-based guidelines for the surveillance and management of CD patients following surgery.

Based the on the evidence reviewed in the present document, we recommend the approach presented in Figure 1 to patients undergoing surgery for CD. First, in considering the management of postoperative $\mathrm{CD}$, it is important to distinguish true prophylaxis - ie, preventive therapy started immediately after surgery - from early treatment, defined as therapy started six to 12 months after surgery when active disease is demonstrated on endoscopy. Second, patients must be stratified into groups with a low risk or high risk of recurrence as defined below:

\section{Low-risk group}

The low-risk group is comprised of patients with no risk factors for recurrence (eg, nonsmokers, first abdominal operation or stricturing disease). This group most likely does not require prophylaxis but, rather, treatment when there is evidence of recurrence. This group should be followed clinically at six months and at one year postsurgery with colonoscopy between six and 12 months, and treated accordingly depending on the clinical and colonoscopic findings.

\section{High-risk group}

The high-risk group includes patients who are smokers, have undergone multiple abdominal surgeries and experienced more complex disease (eg, perforating or fistulizing). These patients should be managed more aggressively. All patients should be encouraged to stop smoking and started on a prophylactic regimen (immediately after surgery) using immunomodulators (eg, AZA, $2.5 \mathrm{mg} / \mathrm{kg} / \mathrm{day}$ or $6-\mathrm{MP}$ $1.5 \mathrm{mg} / \mathrm{kg} /$ day) in combination with a short course (three months) of metronidazole ( $250 \mathrm{mg}$ three times/day).

$\mathrm{CD}$ patients requiring surgical intervention represent a subset of complex patients, and one cannot sufficiently stress the importance of the multidisciplinary approach to these patients. For these proposed management strategies to be implemented and effective, there is a need for an ongoing dialogue between the surgical and gastroenterology teams such that the candidates for prophylaxis are, ideally, identified preoperatively, and that all patients receive appropriate postoperative follow-up and care.

\section{REFERENCES}

1. Baumgart DC, Sandborn WJ. Inflammatory bowel disease: Clinical aspects and established and evolving therapies. Lancet 2007;369:1641-57.

2. Bernstein CN, Blanchard JF, Rawsthorne P, et al. Epidemiology of Crohn's disease and ulcerative colitis in a central Canadian province: A population-based study. Am J Epidemiol 1999;149:916-24.

3. Kappelman MD, Rifas-Shiman SL, Kleinman K, et al. The prevalence and geographic distribution of Crohn's disease and ulcerative colitis in the United States. Clin Gastroenterol Hepatol 2007;5:1424-9

4. Fichera A, Michelassi F. Surgical treatment of Crohn's disease. J Gastrointest Surg 2007;11:791-803.

5. Mekhjian HS, Switz DM, Watts HD, et al. National Cooperative Crohn's Disease Study: Factors determining recurrence of Crohn's disease after surgery. Gastroenterology 1979;77:907-13.

6. Yamamoto T, Fazio VW, Tekkis PP. Safety and efficacy of strictureplasty for Crohn's disease: A systematic review and meta-analysis. Dis Colon Rectum 2007;50:1968-86.

7. Farmer RG, Whelan G, Fazio VW. Long-term follow-up of patients with Crohn's disease. Relationship between the clinical pattern and prognosis. Gastroenterology 1985;88:1818-25.

8. Yamamoto T. Factors affecting recurrence after surgery for Crohn's disease. World J Gastroenterol 2005;11:3971-9.

9. Brouquet A, Blanc B, Bretagnol F, et al. Surgery for intestinal Crohn's disease recurrence. Surgery 2010;148:936-46.

10. Whelan G, Farmer RG, Fazio VW, Goormastic M. Recurrence after surgery in Crohn's disease. Relationship to location of disease (clinical pattern) and surgical indication. Gastroenterology 1985;88:1826-33. 
11. Fichera A, Lovadina S, Rubin M, et al. Patterns and operative treatment of recurrent Crohn's disease: A prospective longitudinal study. Surgery 2006;140:649-54.

12. Rutgeerts P, Geboes K, Vantrappen G, et al. Natural history of recurrent Crohn's disease at the ileocolonic anastomosis after curative surgery. Gut 1984;25:665-72.

13. Anseline PF, Wlodarczyk J, Murugasu R. Presence of granulomas is associated with recurrence after surgery for Crohn's disease: Experience of a surgical unit. Br J Surg 1997;84:78-82.

14. Moskovitz D, McLeod RS, Greenberg GR, et al. Operative and environmental risk factors for recurrence of Crohn's disease. Int J Colorectal Dis 1999;14:224-6.

15. Trnka YM, Glotzer DJ, Kasdon EJ, et al. The long-term outcome of restorative operation in Crohn's disease: Influence of location, prognostic factors and surgical guidelines. Ann Surg 1982;196:345-55.

16. Timmer A, Sutherland LR, Martin F. Oral contraceptive use and smoking are risk factors for relapse in Crohn's disease.

The Canadian Mesalamine for Remission of Crohn's Disease Study Group. Gastroenterology 1998;114:1143-50.

17. Cottone M, Rosselli M, Orlando A, et al. Smoking habits and recurrence in Crohn's disease. Gastroenterology 1994;106:643-8.

18. Ryan WR, Ley C, Allan RN, et al. Patients with Crohn's disease are unaware of the risks that smoking has on their disease. J Gastrointest Surg 2003;7:706-11.

19. Sutherland LR, Ramcharan S, Bryant $\mathrm{H}$, et al. Effect of cigarette smoking on recurrence of Crohn's disease. Gastroenterology 1990;98:1123-8.

20. Yamamoto T, Keighley MR. The association of cigarette smoking with a high risk of recurrence after ileocolonic resection for ileocecal Crohn's disease. Surg Today 1999;29:579-80.

21. Yamamoto T, Keighley MR. Smoking and disease recurrence after operation for Crohn's disease. Br J Surg 2000;87:398-404.

22. Reese GE, Nanidis T, Borysiewicz C, et al. The effect of smoking after surgery for Crohn's disease: A meta-analysis of observational studies. Int J Colorectal Dis 2008;23:1213-21.

23. Poggioli G, Laureti S, Selleri, et al. Factors affecting recurrence in Crohn's disease. Results of a prospective audit. Int J Colorectal Dis 1996;11:294-8.

24. Chardavoyne R, Flint GW, Pollack S, et al. Factors affecting recurrence following resection for Crohn's disease. Dis Colon Rectum 1986;29:495-502.

25. Griffiths AM, Wesson DE, Shandling B, et al. Factors influencing postoperative recurrence of Crohn's disease in childhood. Gut 1991;32:491-5.

26. Rutgeerts P, Geboes K, Vantrappen G, et al. Predictability of the postoperative course of Crohn's disease. Gastroenterology 1990;99:956-63.

27. Bernell O, Lapidus A, Hellers G. Risk factors for surgery and postoperative recurrence in Crohn's disease. Ann Surg 2000;231:38-45.

28. Greenstein AJ, Lachman P, Sachar DB, et al. Perforating and non-perforating indications for repeated operations in Crohn's disease: Evidence for two clinical forms. Gut 1988;29:588-92.

29. McDonald PJ, Fazio VW, Farmer RG, et al. Perforating and nonperforating Crohn's disease. An unpredictable guide to recurrence after surgery. Dis Colon Rectum 1989;32:117-20.

30. Yamamoto T, Allan RN, Keighley MR. Perforating ileocecal Crohn's disease does not carry a high risk of recurrence but usually re-presents as perforating disease. Dis Colon Rectum 1999;42:519-24.

31. Simillis C, Yamamoto T, Reese GE, et al. A meta-analysis comparing incidence of recurrence and indication for reoperation after surgery for perforating versus nonperforating Crohn's disease. Am J Gastroenterol 2008;103:196-205.

32. Wolff BG. Factors determining recurrence following surgery for Crohn's disease. World J Surg 1998;22:364-9.

33. Ellis L, Calhoun P, Kaiser DL, et al. Postoperative recurrence in Crohn's disease. The effect of the initial length of bowel resection and operative procedure. Ann Surg 1984;199:340-7.

34. Wolfson DM, Sachar DB, Cohen A, et al. Granulomas do not affect postoperative recurrence rates in Crohn's disease. Gastroenterology 1982;83:405-9.

35. Avidan B, Sakhnini E, Lahat A, et al. Risk factors regarding the need for a second operation in patients with Crohn's disease. Digestion 2005;72:248-53.

36. Hofer B, Bottger T, Hernandez-Richter T, Seifert JK, Junginger T. The impact of clinical types of disease manifestation on the risk of early postoperative recurrence in Crohn's disease.

Hepatogastroenterology 2001;48:152-5.

37. Fazio VW, Marchetti F, Church M, et al. Effect of resection margins on the recurrence of Crohn's disease in the small bowel. A randomized controlled trial. Ann Surg 1996;224:563-71; discussion 571-3.

38. Yamamoto T, Bain IM, Mylonakis E, et al. Stapled functional end-to-end anastomosis versus sutured end-to-end anastomosis after ileocolonic resection in Crohn disease. Scand J Gastroenterol 1999;34:708-13.

39. Ikeuchi H, Kusunoki M, Yamamura T. Long-term results of stapled and hand-sewn anastomoses in patients with Crohn's disease. Dig Surg 2000;17:493-6.

40. Tersigni R, Alessandroni L, Barreca M, et al. Does stapled functional end-to-end anastomosis affect recurrence of Crohn's disease after ileocolonic resection? Hepatogastroenterology 2003;50:1422-5.

41. Scarpa M, Angriman I, Barollo M, et al. Role of stapled and hand-sewn anastomoses in recurrence of Crohn's disease. Hepatogastroenterology 2004;51:1053-7.

42. McLeod RS, Wolff BG, Ross S, et al. Recurrence of Crohn's disease after ileocolic resection is not affected by anastomotic type: Results of a multicenter, randomized controlled trial. Dis Colon Rectum 2009;52:919-27.

43. Tan JJ, Tjandra JJ. Laparoscopic surgery for Crohn's disease: A meta-analysis. Dis Colon Rectum 2007;50:576-85.

44. Fichera A, Peng SL, Elisseou NM, Rubin MA, Hurst RD. Laparoscopy or coventional open surgery for patients with ileocolonic Crohn's disease? A prospective study. Surgery 2007;142:566-71.

45. Eshuis EJ, Polle SW, Slors JF, et al. Long-term surgical recurrence, morbidity, quality of life, and body image of laparoscopic-assisted vs. open ileocolic resection for Crohn's disease: A comparative study. Dis Colon Rectum 2008;51:858-67.

46. Stocchi L, Milsom JW, Fazio VW. Long-term outcomes of laparoscopic versus open ileocolic resection for Crohn's disease: Follow-up of a prospective randomized trial. Surgery 2008;144:622-7; discussion 627-8.

47. Okabayashi K, Hasegawa $\mathrm{H}$, Watanabe M, et al. Indications for laparoscopic surgery for Crohn's disease using the Vienna classification. Colorectal Disease 2007;9:825-9.

48. Castiglione F, de Sio I, Cozzolino A, et al. Bowel wall thickness at abdominal ultrasound and the one-year-risk of surgery in patients with Crohn's disease. Am J Gastroenterol 2004;99:1977-83.

49. Maconi G, Sampietro GM, Cristaldi M, et al. Preoperative characteristics and postoperative behavior of bowel wall on risk of recurrence after conservative surgery in Crohn's disease: A prospective study. Ann Surg 2001;233:345-52.

50. Parente F, Sampietro GM, Molteni M, et al. Behaviour of the bowel wall during the first year after surgery is a strong predictor of symptomatic recurrence of Crohn's disease: A prospective study. Aliment Pharmacol Ther 2004;20:959-68.

51. Yamamoto T, Umegae S, Kitagawa T, et al. Mucosal cytokine production during remission after resection for Crohn's disease and its relationship to future relapse. Aliment Pharmacol Ther 2004;19:671-8.

52. Meresse B, Rutgeerts $\mathrm{P}$, Malchow $\mathrm{H}$, et al. Low ileal interleukin 10 concentrations are predictive of endoscopic recurrence in patients with Crohn's disease. Gut 2002;50:25-8.

53. Alvarez-Lobos M, Arostegui JI, Sans M, et al. Crohn's disease patients carrying Nod2/CARD15 gene variants have an increased and early need for first surgery due to stricturing disease and higher rate of surgical recurrence. Ann Surg 2005;242:693-700.

54. Seiderer J, Brand S, Herrmann KA, et al. Predictive value of the CARD15 variant $1007 \mathrm{fs}$ for the diagnosis of intestinal stenoses and the need for surgery in Crohn's disease in clinical practice: Results of a prospective study. Inflamm Bowel Dis 2006;12:1114-21.

55. Spivak J, Landers CJ, Vasiliauskas EA, et al. Antibodies to I2 predict clinical response to fecal diversion in Crohn's disease. Inflamm Bowel Dis 2006;12:1122-30.

56. Biancone L, Onali S, Calabrese E, et al. Non-invasive techniques for assessing postoperative recurrence in Crohn's disease. Dig Liver Dis 2008;40(Suppl 2):S265-70.

57. Sailer J, Peloschek P, Reinisch W, et al. Anastomotic recurrence of Crohn's disease after ileocolic resection: Comparison of MR enteroclysis with endoscopy. Eur Radiol 2008;18:2512-21.

58. Calabrese E, La Seta F, Buccellato A, et al. Crohn's disease: A comparative prospective study of transabdominal ultrasonography, 
small intestine contrast ultrasonography, and small bowel enema. Inflamm Bowel Dis 2005;11:139-45.

59. Castiglione F, Bucci L, Pesce G, et al. Oral contrast-enhanced sonography for the diagnosis and grading of postsurgical recurrence of Crohn's disease. Inflamm Bowel Dis 2008;14:1240-5.

60. Schreiber S, Nikolaus S, Hampe J, et al. Tumour necrosis factor alpha and interleukin 1beta in relapse of Crohn's disease. Lancet 1999;353:459-61.

61. Van Kemseke C, Belaiche J, Louis E. Frequently relapsing Crohn's disease is characterized by persistent elevation in interleukin- 6 and soluble interleukin-2 receptor serum levels during remission. Int J Colorectal Dis 2000;15:206-10.

62. Papadakis KA, Yang H, Ippoliti A, et al. Anti-flagellin (CBir1) phenotypic and genetic Crohn's disease associations. Inflamm Bowel Dis 2007;13:524-30.

63. Devlin SM, Yang H, Ippoliti A, et al. NOD2 variants and antibody response to microbial antigens in Crohn's disease patients and their unaffected relatives. Gastroenterology 2007;132:576-86.

64. Summers RW, Switz DM, Sessions JT, et al. National Cooperative Crohn's Disease Study: Results of drug treatment. Gastroenterology 1979;77:847-69.

65. Wenckert A, Kristensen M, Eklund AE, et al. The long-term prophylactic effect of salazosulphapyridine (Salazopyrin) in primarily resected patients with Crohn's disease. A controlled double-blind trial. Scand J Gastroenterol 1978;13:161-7.

66. Ewe K, Herfarth C, Malchow H, Jesdinsky HJ.

Postoperative recurrence of Crohn's disease in relation to radicality of operation and sulfasalazine prophylaxis: A multicenter trial. Digestion 1989;42:224-32.

67. Caprilli R, Andreoli A, Capurso L, et al. Oral mesalazine (5-aminosalicylic acid; Asacol) for the prevention of post-operative recurrence of Crohn's disease. Gruppo Italiano per lo Studio del Colon e del Retto (GISC). Aliment Pharmacol Ther 1994;8:35-43.

68. McLeod RS, Wolff BG, Steinhart AH, et al. Prophylactic mesalamine treatment decreases postoperative recurrence of Crohn's disease. Gastroenterology 1995;109:404-13.

69. Brignola C, Cottone M, Pera A, et al. Mesalamine in the prevention of endoscopic recurrence after intestinal resection for Crohn's disease. Italian Cooperative Study Group. Gastroenterology 1995; $108: 345-9$

70. Florent C, Cortot A, Quandale P, et al. Placebo-controlled clinical trial of mesalazine in the prevention of early endoscopic recurrences after resection for Crohn's disease. Groupe d'Etudes Therapeutiques des Affections Inflammatoires Digestives (GETAID).

Eur J Gastroenterol Hepatol 1996;8:229-33.

71. Sutherland LR, Martin F, Bailey RJ, et al. A randomized, placebo-controlled, double-blind trial of mesalamine in the maintenance of remission of Crohn's disease. The Canadian Mesalamine for Remission of Crohn's Disease Study Group. Gastroenterology 1997;112:1069-77.

72. Lochs H, Mayer M, Fleig WE, et al. Prophylaxis of postoperative relapse in Crohn's disease with mesalamine: European Cooperative Crohn's Disease Study VI. Gastroenterology 2000;118:264-73.

73. Caprilli R, Cottone M, Tonelli F, et al. Two mesalazine regimens in the prevention of the post-operative recurrence of Crohn's disease: A pragmatic, double-blind, randomized controlled trial. Aliment Pharmacol Ther 2003;17:517-23.

74. Hanauer SB, Korelitz BI, Rutgeerts P, et al. Postoperative maintenance of Crohn's disease remission with 6-mercaptopurine, mesalamine, or placebo: A 2-year trial. Gastroenterology 2004;127:723-9.

75. Doherty G, Bennett G, Patil S, et al. Interventions for prevention of post-operative recurrence of Crohn's disease. Cochrane Database Syst Rev 2009;4:CD006873.

76. Cuillerier E, Lemann M, Bouhnik Y, et al. Azathioprine for prevention of postoperative recurrence in Crohn's disease: A retrospective study. Eur J Gastroenterol Hepatol 2001;13:1291-6.

77. Domenech E, Scala L, Bernal I, et al. [Azathioprine and mesalazine in the prevention of postsurgical recurrence of Crohn's disease: A retrospective study.] Gastroenterol Hepatol 2004;27:563-7.

78. Unkart JT, Anderson L, Li E, et al. Risk factors for surgical recurrence after ileocolic resection of Crohn's disease. Dis Colon Rectum 2008;51:1211-6.

79. D'Haens GR, Vermeire S, Van Assche G, et al. Therapy of metronidazole with azathioprine to prevent postoperative recurrence of Crohn's disease: A controlled randomized trial. Gastroenterology 2008;135:1123-9.
80. Sandborn WJ, Feagan BG. The efficacy of azathioprine and 6-mercaptopurine for the prevention of postoperative recurrence in patients with Crohn's disease remains uncertain. Gastroenterology 2004;127:990-3.

81. Ardizzone S, Maconi G, Sampietro GM, et al. Azathioprine and mesalamine for prevention of relapse after conservative surgery for Crohn's disease. Gastroenterology 2004;127:730-40.

82. Alves A, Panis Y, Joly F, et al. Could immunosuppressive drugs reduce recurrence rate after second resection for Crohn disease? Inflamm Bowel Dis 2004;10:491-5.

83. Domenech E, Manosa M, Bernal I, et al. Impact of azathioprine on the prevention of postoperative Crohn's disease recurrence: Results of a prospective, observational, long-term follow-up study. Inflamm Bowel Dis 2008;14:508-13.

84. Renna S, Camma C, Modesto I, et al. Meta-analysis of the placebo rates of clinical relapse and severe endoscopic recurrence in postoperative Crohn's disease. Gastroenterology 2008;135:1500-9.

85. Bergman L, Krause U. Postoperative treatment with corticosteroids and salazosulphapyridine (Salazopyrin) after radical resection for Crohn's disease. Scand J Gastroenterol 1976;11:651-6.

86. Hellers G, Cortot A, Jewell D, et al. Oral budesonide for prevention of postsurgical recurrence in Crohn's disease. The IOIBD Budesonide Study Group. Gastroenterology 1999;116:294-300.

87. Ewe K, Bottger T, Buhr HJ, et al. Low-dose budesonide treatment for prevention of postoperative recurrence of Crohn's disease: A multicenter randomized placebo-controlled trial. German Budesonide Study Group. Eur J Gastroenterol Hepatol 1999;11:277-82.

88. Benchimol EI, Seow CH, Otley AR, et al. Budesonide for maintenance of remission in Crohn's disease. Cochrane Database Syst Rev 2009;21(1):CD002913.

89. Rutgeerts P, Hiele M, Geboes K, et al. Controlled trial of metronidazole treatment for prevention of Crohn's recurrence after ileal resection. Gastroenterology 1995;108:1617-21.

90. Rutgeerts P, Van Assche G, Vermeire S, et al. Ornidazole for prophylaxis of postoperative Crohn's disease recurrence: A randomized, double-blind, placebo-controlled trial. Gastroenterology 2005;128:856-61.

91. Boirivant M, Strober W. The mechanism of action of probiotics. Curr Opin Gastroenterol 2007;23:679-92.

92. Prantera C, Scribano ML, Falasco G, Andreoli A, Luzi C. Ineffectiveness of probiotics in preventing recurrence after curative resection for Crohn's disease: A randomised controlled trial with Lactobacillus GG. Gut 2002;51:405-9.

93. Marteau P, Lemann M, Seksik P, et al. Ineffectiveness of Lactobacillus johnsonii LA1 for prophylaxis of postoperative recurrence in Crohn's disease: A randomised, double blind, placebo controlled GETAID trial. Gut 2006;55:842-7.

94. Van Gossum A, Dewit O, Louis E, et al. Multicenter randomizedcontrolled clinical trial of probiotics (Lactobacillus johnsonii, LA1) on early endoscopic recurrence of Crohn's disease after lleo-caecal resection. Inflamm Bowel Dis 2007;13:135-42.

95. Chermesh I, Tamir A, Reshef R, et al. Failure of Synbiotic 2000 to prevent postoperative recurrence of Crohn's disease. Dig Dis Sci 2007;52:385-9.

96. Madsen K, Backer JL, Leddin D, et al. A randomized controlled trial of $\mathrm{Vsl} \# 3$ for the preventon of endoscopic recurrance following surgery for Crohn's disease. Gastroenterol 2008;134:A361.

97. Sorrentino D, Terrosu G, Avellini C, et al. Prevention of postoperative recurrence of Crohn's disease by infliximab. Eur J Gastroenterol Hepatol 2006;18:457-9.

98. Sorrentino D, Terrosu G, Avellini C, et al. Infliximab with low-dose methotrexate for prevention of postsurgical recurrence of ileocolonic Crohn disease. Arch Intern Med 2007;167:1804-7.

99. Regueiro M, Schraut W, Baidoo L, et al. Infliximab prevents Crohn's disease recurrence after ileal resection. Gastroenterology 2009;136:441-50 e1; quiz 716.

100. Yamamoto T, Umegae, Matsumoto K. Impact of infliximab therapy after early endoscopic recurrence following ileocolonic resection of Crohn's disease: A prospective pilot study. Inflamm Bowel Dis 2009;25:1460-6.

101. Meresse B, Rutgeerts P, Malchow H, et al. Low ileal interleukin 10 concentrations are predictive of endoscopic recurrence in patients with Crohn's disease. Gut 2002;50:25-8.

102. Colombel JF, Rutgeerts P, Malchow H, et al. Interleukin 10 (Tenovil) in the prevention of postoperative recurrence of Crohn's disease. Gut 2001;49:42-6. 


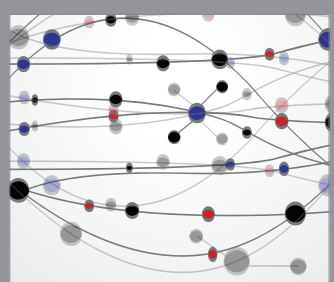

The Scientific World Journal
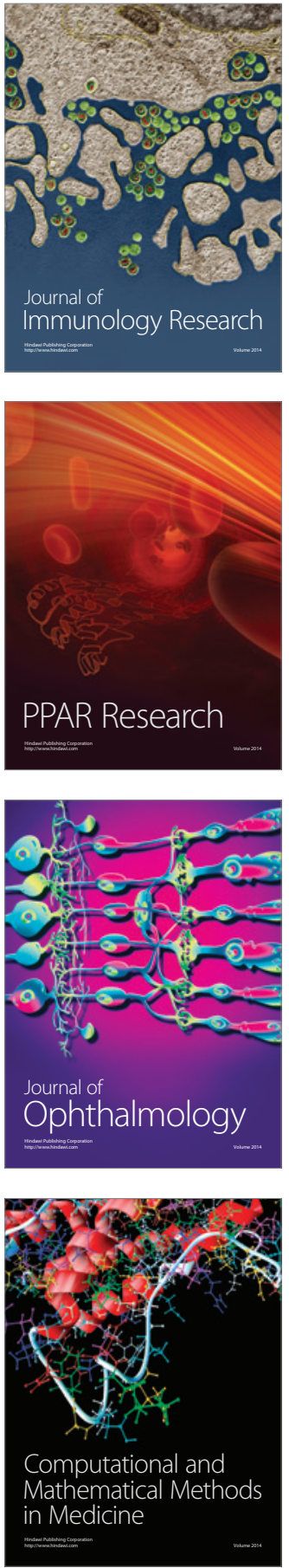

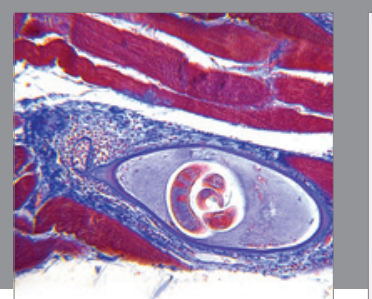

Gastroenterology Research and Practice

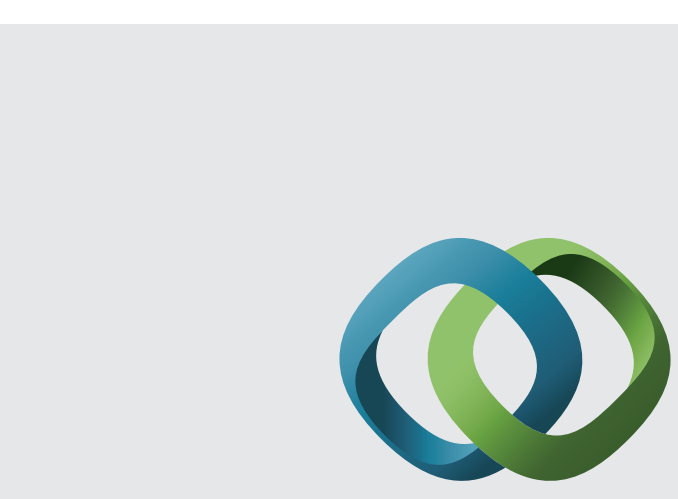

\section{Hindawi}

Submit your manuscripts at

http://www.hindawi.com
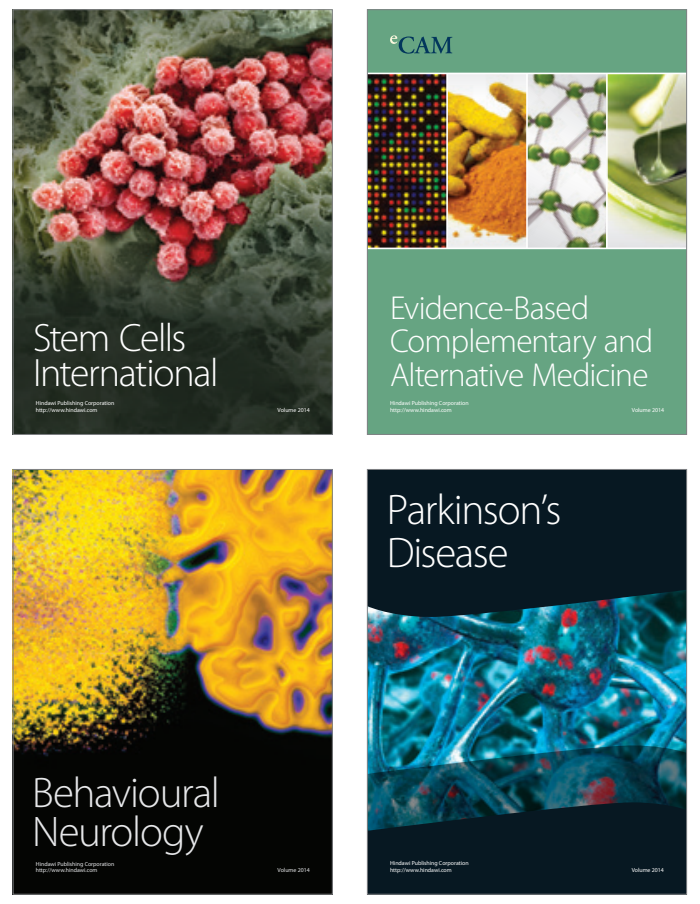
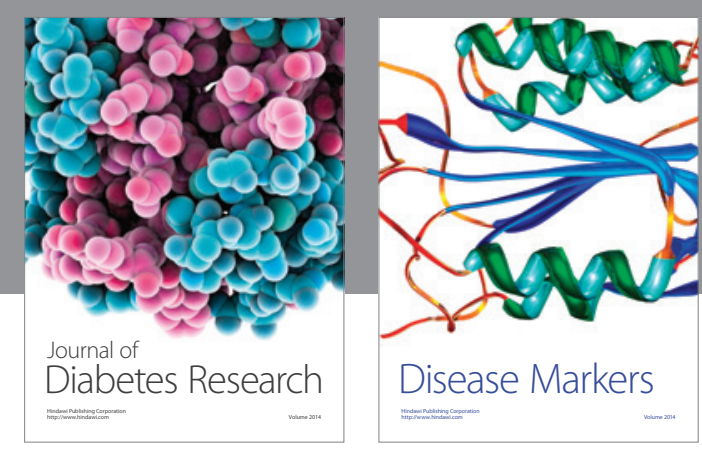

Disease Markers
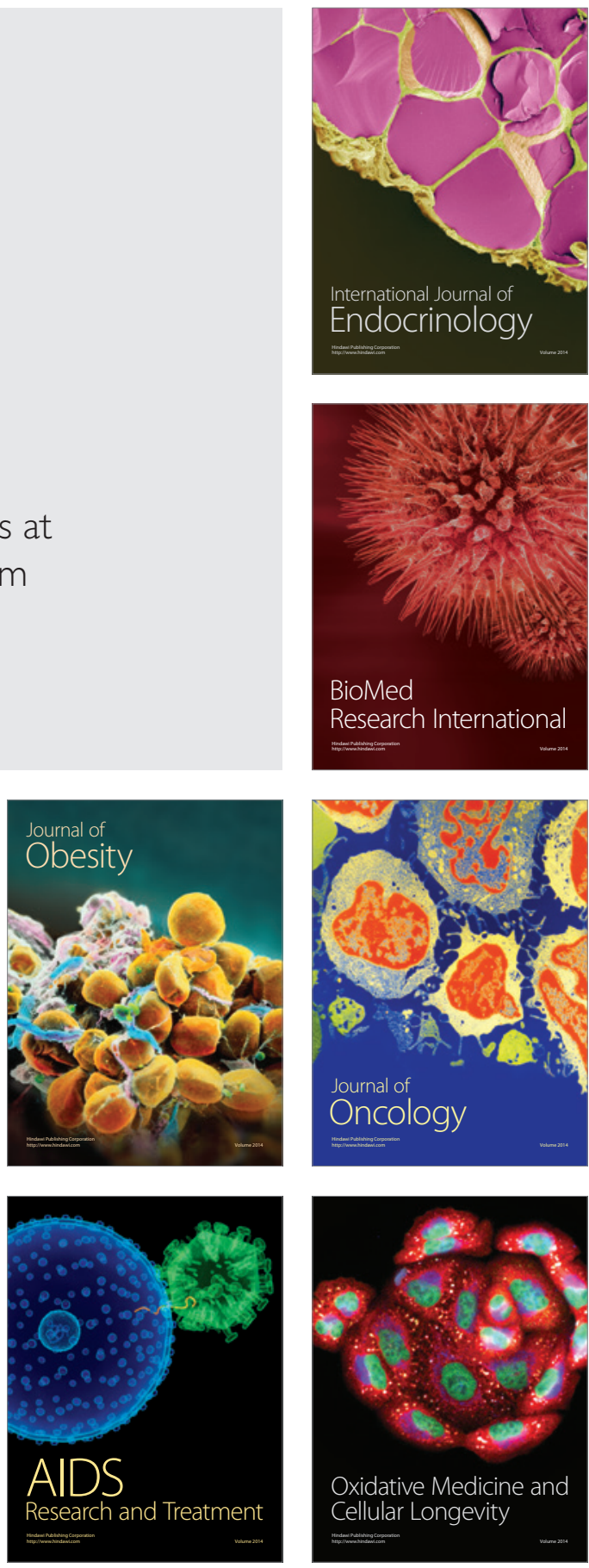